\title{
Genome-Wide Identification and Analysis of the Valine-Glutamine Motif- Containing Gene Family in Brassica napus and Functional Characterization of BnMKS1 in Response to Leptosphaeria maculans
}

\author{
Zhongwei Zou, Fei Liu, Shuanglong Huang, and W. G. Dilantha Fernando ${ }^{\dagger}$ \\ Department of Plant Science, University of Manitoba, Winnipeg, Manitoba R3T 2N2, Canada \\ Accepted for publication 13 August 2020.
}

ABSTRACT

\begin{abstract}
Proteins containing valine-glutamine (VQ) motifs play important roles in plant growth and development as well as in defense responses to both abiotic and biotic stresses. Blackleg disease, which is caused by Leptosphaeria maculans, is the most important disease in canola (Brassica napus) worldwide; however, the identification of Brassica napus VQs and their functions in response to blackleg disease have not yet been reported. In this study, we conducted a genome-wide identification and characterization of the $V Q$ gene family in Brassica napus, including chromosome location, phylogenetic relations, gene structure, motif domain, synteny analysis, and cis-elements categorization of their promoter regions. To understand Brassica napus $V Q$ gene function in response to blackleg disease, we overexpressed BnVQ7 (BnaA01g36880D, also known as the mitogen-activated protein kinase 4 substrate 1 [MKS1] gene) in a blacklegsusceptible canola variety, Westar. Overexpression of BnMKS1 in canola
\end{abstract}

did not improve its resistance to blackleg disease at the seedling stage; however, transgenic canola plants overexpressing BnMKS1 displayed an enhanced resistance to $L$. maculans infection at the adult plant stage. Expression levels of downstream and defense marker genes in cotyledons increased significantly at the necrotrophic stage of $L$. maculans infection in the overexpression line of BnMKS1, suggesting that the salicylic acid- and jasmonic acid-mediated signaling pathways were both involved in the defense responses. Together, these results suggest that BnMKS1 might play an important role in defense against $L$. maculans.

Keywords: abiotic disorders, Brassica napus, fungal pathogens, genetics, genomics, host parasite interactions, Leptosphaeria maculans, MKS1, pathogen recognition by plants, plant stress, resistance, VQ motifcontaining proteins
Valine-glutamine (VQ) motif-containing proteins are encoded by Valine-glutamine genes, designated as the highly conserved motif structure FxxhVQxhTG, and were identified in both monocotyledon and dicotyledonous plants (Cheng et al. 2012; Kim et al. 2013; Wang et al. 2014, 2015). A 2018 study showed that VQs are nonplant specific and play a comprehensive function in various biotic and abiotic stresses. Single VQs to very few VQs were also found in some fungi, taxonomically lower animals, and bacteria (Jiang et al. 2018). In Arabidopsis (Arabidopsis thaliana), AtVQ8 contains an $\mathrm{N}$-terminal signal peptide and is understood to be a chloroplast-targeting signal. Leaves of the $v q 8$ mutant presented pale-green and stunted growth because of abnormal chloroplast development (Cheng et al. 2012). AtVQ14 (IKU1-protein HAIKU1) has been characterized to function in the early stages of seed development and growth, whereas AtVQ29 is involved in hypocotyl growth under far-red and low-white light intensity (Li et al. 2014a; Wang et al. 2010). VQs are up- or downregulated by abiotic stresses or phytohormones in rice (Kim et al. 2013), maize (Song et al. 2016), and Chinese cabbage (Zhang et al. 2015). VQs were reported to display

†Corresponding author: W. G. D. Fernando; Dilantha.Fernando@umanitoba.ca

Funding: This work was funded by the Natural Sciences and Engineering Research Council of Canada Discovery Program (RGPIN227097-2012) and CRD (CRDPJ43673312) and funds awarded by the SaskCanola GF2 and CAP/GF3 programs (grant 330578) to W. G. D. Fernando.

Z. Zou and F. Liu contributed equally to this work.

*The $e$-Xtra logo stands for "electronic extra" and indicates that four supplementary figures and three supplementary tables are published online.

The author(s) declare no conflict of interest. different expression patterns in Arabidopsis thaliana, rice, and other plants under biotic stresses (Cheng et al. 2012; Jiang and Yu 2016; Kim et al. 2013; Li et al. 2014b; Wang et al. 2015). VQs are also considered regulators, interacting with other proteins such as WRKY transcription factors in plant growth and development (Cheng et al. 2012; Chi et al. 2013). For example, AtVQ9 interacts with WRKY8, has a mediated response to salt stress, and decreases the tDNA binding activity of WRKY8 (Hu et al. 2013). Both AtVQ1 and AtVQ10 were reported to interact with WRKY33 and be closely related to WRKY25 and WRKY26 (Cheng et al. 2012; Lai et al. 2011). AtVQ21, which was renamed mitogen-activated protein kinase 4 substrate 1 (MKS1) and acts as a substrate of mitogen-activated protein (MAP) kinase 4 (MPK4), has also been found to interact with AtWRKY33 (Andreasson et al. 2005). MKS1 plays an important role in response to plant pathogens through its interaction with AtWRKY33 and AtMPK4 (i.e., Botrytis cinerea, Sclerotinia sclerotiorum; Wang et al. 2009; Zheng et al. 2006). Wang et al. $(2009,2014)$ reported that the overexpression of BnMPK4 and BnWRKY33 enhanced resistance to S. sclerotiorum in Brassica napus. BnMKS1, encoding one of the VQ-motif proteins in Brassica napus, was characterized as being able to interact with both BnMPK4 and BnWRKY33, resulting in a nuclear-localized complex, which allows for disease resistance in canola (Wang et al. 2014).

Canola (Brassica napus L. AACC, $2 \mathrm{n}=38$ ) is a relatively young allotetraploid species that was derived from the hybridization between the ancestors of Brassica rapa L. (AA, $2 \mathrm{n}=20$ ) and Brassica oleracea L. (CC, $2 \mathrm{n}=18$ ) (Nagaharu 1935). Canola/ rapeseed oil is the third most-used crop for oil production, following palm oil and soybean worldwide, and is one of the most important economical crops in Canada (Canola Council of Canada 2020; Gunstone 2011). Genome-wide identification of gene families has been widely reported since several genomes sequences of Brassica napus were published (Chalhoub et al. 2014; Sun et al. 2017). A total of 518 AP2/EREBPs, 252 BnbZIPs, 721 BnMYBs, 398 BnNACs, 278 BnWRKYs, 87 GRASs, and 460 bHLHs belonging to 
transcription factors have been characterized from Brassica napus genome sequences (Guo et al. 2019; Shen et al. 2019; Wang et al. 2018). Wei et al. (2019) reported 179 glutathione transferase genes in Brassica napus through genome-wide analysis. A total of 47 Hsp70 genes, which play an important role in plant growth and stress responses, have been identified in Brassica napus (Liang et al. 2019). Other gene families, including 67 auxin response factors (Wen et al. 2019), 121 aquaporins (Yuan et al. 2017), and 23 cytokinin oxidase/dehydrogenases (Liu et al. 2018a), were extensively reported. To date, genome-wide studies have been applied to identify a total of $34,74,61,57$, and $18 V Q$ s from Arabidopsis plants (Jing and Lin 2015), soybean (Zhou et al. 2016), maize (Song et al. 2016), Chinese cabbage (Zhang et al. 2015), and grape (Wang et al. 2015), respectively. To our knowledge, the $V Q$ gene family from Brassica napus has not yet been characterized in detail.

In Canada, canola fields encounter various biotic stresses, especially from diseases (i.e., blackleg, clubroot, and Sclerotinia stem rot). Blackleg disease is caused by Leptosphaeria maculans and is one of the most devastating diseases worldwide, resulting in significant yield loss (Fernando et al. 2016; Fitt et al. 2006). Brassica napus and L. maculans exist in a gene-for-gene interaction between the $R$ gene in the plant and its corresponding avirulence gene $(A v r)$ in the host, which results in both compatible and incompatible interactions (Ansan-Melayah et al. 1997; Balesdent et al. 2002). L. maculans is a hemibiotrophic fungus, which includes biotrophic and necrotrophic stages when infecting canola plants. For example, when L. maculans infects canola plant leaves, the fungus has a 5- to 15-day biotrophic stage and colonizes the plant leaf apoplast (Fitt et al. 2006). The fungus then causes leaf spots and reaches the necrotrophic stage (Rouxel and Balesdent 2005); however, when L. maculans infects the cotyledons of canola seedlings in compatible interactions, the fungus most likely stays in the biotrophic stage at 0,2 , and 4 days postinoculation (dpi) and turns to the necrotrophic stage at 6 or 8 dpi (Haddadi et al. 2016). In the biotrophic stage, there are no obvious visible disease symptoms for the first $4 \mathrm{dpi}$, and a clear chlorotic ring surrounding the wound site can be observed at 4 to $6 \mathrm{dpi}$. Later ( $8 \mathrm{dpi}$ ), it expands and leads to lesion formation and tissue collapse, indicating that L. maculans likely switches to necrotrophy (Haddadi et al. 2016). A similar study investigated the comparative transcriptomes of virulence factors involved in biotrophic (7 dpi) and necrotrophic (11 dpi) stages during compatible interactions between Brassica napus and L. maculans (Sonah et al. 2016). Very few studies were published that report an investigation of the functional genes in response to blackleg disease. A better understanding of the $V Q$ genes involved in disease resistance will provide new insights for disease management. In this study, we characterized the VQ-motif proteins in Brassica napus by using genome-wide bioinformatics analysis, such as genome locations, promoter analysis, gene structures, conserved domains, duplication patterns, and karyotype and phylogenetic relations with Arabidopsis thaliana, Brassica rapa, and Brassica oleracea. The expression patterns of these genes in response to blackleg disease were analyzed. Overexpression of $B n M K S 1$ (one of the $B n V Q$ genes) enhances the adult plant resistance of Brassica napus in response to blackleg disease.

\section{MATERIALS AND METHODS}

Identification of Brassica napus $V Q$ gene family members. The 34 AtVQ protein sequences retrieved from the Arabidopsis thaliana genome (https://www.arabidopsis.org/) were used to identify VQ genes in Brassica napus by a BLASTP search (Altschul et al. 1997). BLASTP was searched using default parameters with an E-value of $\leq 1 \times 10^{-20}$ and the score set $\geq$ 1,000. Brassica napus genome sequences were obtained from a recent version of Centre National de Sequençage (http://www.genoscope.cns.fr/brassicanapus/; Chalhoub et al. 2014). To confirm the identified $B n V Q$ s, the obtained sequences were searched against the Arabidopsis thaliana protein database again. The identified VQ protein sequences were analyzed using the Batch CD-Search to ensure that the target proteins contained VQ motifs (https:// www.ncbi.nlm.nih.gov/Structure/bwrpsb/bwrpsb.cgi). The Brassica napus, Brassica rapa, Brassica oleracea, and Arabidopsis thaliana VQ protein sequences were used for multiple sequence alignments (ClustalW) and the phylogenetic tree was established in MEGA 6.0 using neighbor-joining method with bootstrap calculation as 1,000 replications (Tamura et al. 2013).

Chromosomal location, orthologous identification, and karyotype of Brassica napus VQs. Chromosomal locations of Brassica napus $V Q$ genes were determined based on the Brassica napus Genome Browser and were mapped by using MapChart 2.2 (Voorrips 2002). The collinearity relationships and gene duplication types of identified Brassica napus $V Q$ genes were analyzed via MCScanX (Wang et al. 2012b). Self-self-comparison of Brassica napus VQ protein sequences were conducted by BASTP (E-value $\leq$ $\left.1 \times 10^{-10}\right)$. The program in MCScanX, detect_collinearity_within_ gene_families.pl, was introduced to detect collinearity within the Brassica napus VQ gene family (Wang et al. 2012b). A built-in program within MCScanX was applied to classify the origins of the duplicate genes of the Brassica napus genome with five duplication types, including whole-genome duplication (WGD), segmental duplication, tandem duplication, and rearrangements. In addition, duplication information of the Brassica napus VQs was extracted and displayed using the circle_plotter program in MCScanX. Karyotype and synteny from Arabidopsis thaliana and three Brassica species (Brassica rapa, Brassica oleracea, and Brassica napus) were analyzed and visualized in jcvi (https://github.com/ tanghaibao/jcvi/blob/master/jcvi/graphics/karyotype.py).

Gene structures and protein-conserved domain analysis of the $V Q$ gene family in Brassica napus. The intron/exon structures of Brassica napus VQs were retrieved from the generic feature format files and drawn using TBtools software (Chen et al. 2018). To assess the structural divergence of Brassica napus VQs, the conserved domains of identified VQ proteins were investigated using the Batch CDD tool (https://www.ncbi.nlm.nih.gov/Structure/bwrpsb/bwrpsb.cgi) with default parameters and displayed by TBtools (Chen et al. 2018).

Promoter analysis. A total of 2,000-bp upstream sequences of the coding region of each predicted $V Q$ gene were obtained from the Brassica napus genome database. The promoter sequences of each Brassica napus $V Q$ were screened for cis-acting regulatory elements using the PlantCARE database (http://bioinformatics.psb.ugent.be/webtools/plantcare/html/). The PlantCARE database was also employed to identify putative plant-specific transcription factor binding sites using a given DNA sequence.

Plant growth and fungal materials. Brassica napus 'Westar', which is a spring canola cultivar and susceptible to blackleg disease, was used in this study. Plants were grown in a plant growth chamber at $16^{\circ} \mathrm{C}$ (night) and $21^{\circ} \mathrm{C}$ (day) with a $16-\mathrm{h}$ photoperiod/day. L. maculans isolate JN3 having AvrLm1-4-5-6-7-810 was used for inoculation (Rouxel et al. 2011). The isolate was grown and maintained on a V8 medium plate (Zou et al. 2018, 2019).

Plasmid construction for canola transformation. The total RNA from the canola plant Westar leaves was isolated using PureLink Plant RNA Reagent (Invitrogen, Carlsbad, CA). The purified RNA was then digested with DNase at $37^{\circ} \mathrm{C}$ for $30 \mathrm{~min}$ to degrade the genomic DNA using a TURBO DNA-free kit (Invitrogen). The first-strand cDNA was synthesized from $1 \mu \mathrm{g}$ of total RNA using the first cDNA synthesis kit (Thermo Scientific, Waltham, MA). The In-Fusion cloning strategy was applied to design the overexpression primers to ligate the full-length cDNA of BnMKS1 (BnVQ7: BnaA01g36880D) to pRI201-AN vector having a Cauliflower mosaic virus (CaMV) 35S promoter (catalog number 3264; Takara Bio USA, Mountain View, CA; https://www.takarabio.com/learning-centers/cloning/in-fusion-cloning-tools). The 
primers were CACTGTTGATACATATGGATCCGTCGGAGTCTTTCGCCGGC and ATTCAGAATTGTCGATTATCCCCAAATATGACTGAACAAATCAGC. The inserted fragment was confirmed by digestion with restriction enzymes $\mathrm{SacI}$ and NdeI (New England Biolabs, Ipswich, MA) and sequencing. Then the construct pRI201-AN-35S-BnMKS1-NOS was transformed into Agrobacterium tumefaciens (LBA4404). Hypocotyl explants of Westar were used for the generation of overexpressed transgenic lines by in planta Agrobacterium-mediated transformation according to the protocol described previously (De Block et al. 1989). Two independent transformants overexpressing BnMKS1 were examined using quantitative PCR (qPCR) (Supplementary Table S1). Kanamycin-resistant $T_{2}$ generation plants were identified by PCR from the $T_{0}$ transgenic lines.

Cotyledon inoculation and adult plant resistance screening. The concentration of harvested pycnidiospore suspension of $L$. maculans isolate JN3 was adjusted to $2 \times 10^{7} \mathrm{spores} / \mathrm{ml}$ for cotyledon inoculation testing (major gene resistance). Cotyledons of 7-day-old seedlings of Westar and transgenic lines of $\mathrm{T}_{0}$ and $\mathrm{T}_{2}$ plants were punched and inoculated with $10 \mu \mathrm{l}$ of inoculum at each of the two wound sites (24 wound sites for six plants) (Zou et al. 2018). The disease rating scores were recorded at $14 \mathrm{dpi}$ as described by Zhang et al. (2016). Disease rating scores from 6.1 to $9.0,4.6$ to 6.0 , and $<4.5$ were considered as susceptible, intermediate resistant, and resistant, respectively (Zhang et al. 2016; Zou et al. 2018, 2019). The lesion sizes of infected cotyledons were quantified using Assess 2.0 (American Phytopathological Society, St. Paul, MN) for each experiment and line. Statistical analysis was performed using SAS version 9.4 for analysis of variance and mean comparison using Tukey's honest significant difference studentized test at $P \leq 0.05$.

The cotyledon inoculated seedlings were transplanted to pots and placed in a growth room at $16^{\circ} \mathrm{C}$ (night) and $21^{\circ} \mathrm{C}$ (day) with a $16-\mathrm{h}$ photoperiod to evaluate the adult plant resistance of Westar and overexpression $\mathrm{T}_{2}$ lines, which was from $\mathrm{T}_{1}$ lines showing the highest expression of BnMKS1. Finally, plant disease severity was scored from basal internal infection using a rating scale from 0 to 5 (West et al. 2001). The rating scale was as follows: 0 , no disease; 1 , $25 \%$ infection; 2, $50 \%$ infection; $3,75 \%$ infection; $4,100 \%$ infection; and 5, 100\% infection and plant death.

Sampling, RNA extraction, and real-time qPCR analysis. Cotyledons of Westar and transgenic overexpressing line 7 (OEBnMKS1-7) inoculated with L. maculans isolate JN3 were sampled at 7 and $11 \mathrm{dpi}$. RNA extraction and cDNA synthesis were conducted as described above. cDNA was diluted 100 times for the qPCR assay: $4.2 \mu \mathrm{l}$ of cDNA, $5 \mu \mathrm{l}$ of SYBR Green I Master Mix (Clontech, Palo Alto, CA), and $0.4 \mu \mathrm{l}$ of each primer $(10 \mathrm{mM})$. The primers used for BnMKS1, the reference gene (Brassica napus actin: AF111812.2), and downstream genes are listed in Supplementary Table S1 (Liu et al. 2018b). The qPCR cycling was set to $95^{\circ} \mathrm{C}$ for $1 \mathrm{~min}, 40$ cycles of $95^{\circ} \mathrm{C}$ for $10 \mathrm{~s}, 60^{\circ} \mathrm{C}$ for $30 \mathrm{~s}$, followed by $95^{\circ} \mathrm{C}$ for 10 min using a CFX96 real-time instrument (Bio-Rad, Hercules, CA). The temperature of $0.5^{\circ} \mathrm{C}$ at $5 \mathrm{~s} / \mathrm{step}$ from 65 to $95^{\circ} \mathrm{C}$ was used to estimate the specificity of the product for melting curve analysis. Relative gene expression was calculated according to the $2^{-\Delta \Delta \mathrm{CT}}$ method (Livak and Schmittgen 2001). All experiments were conducted from three biologically independent RNA samples and three replicates for each $\mathrm{qPCR}$ assay.

\section{RESULTS}

Genome-wide identification of $V Q$ genes in Brassica napus. A total of 118 genes were identified from Brassica napus genome sequences, which encoded highly conserved VQ motifcontaining proteins. All $V Q \mathrm{~s}$ were assigned specific names according to their locations in the Brassica napus genome. A total of eight VQs (BnVQ111 to BnVQ118) could not be assigned to any of the chromosomes of Brassica napus since the contigs containing these genes were not located on any chromosome. The number of $V Q$ s on each chromosome ranged from 3 to 10 : chromosome $\mathrm{C} 03$ had $10 \mathrm{VQs}$, whereas both chromosomes A06 and C09 only had three (Supplementary Fig. S1; Supplementary Table S2). The predicted protein length of BnVQs varied from 90 to 1,040 amino acids. The majority of the protein length contained $\leq 300$ amino acids $(103$ of $118 ; 87.3 \%$ ) (Supplementary Table S2). A total of 15 BnVQs had >300 amino acid sequences; one, BnVQ51, was located at ChrA09 and had 1,040 amino acids (Supplementary Table S2). The molecular weight of the identified BnVQs ranged from 10.0 to $117.6 \mathrm{kDa}$, with an average of $25.3 \mathrm{kDa}$ (Supplementary Table S2). Additionally, the theoretical isoelectric point was distributed from 4.36 to 10.97 (Supplementary Table S2). Four duplication models, including WGD, dispersed, tandem, and proximal, were detected in 118 BnVQ genes (Supplementary Table S2). Among them, 105 $B n V Q$ genes were produced by WGD and 10 were produced by dispersed duplications. Two and one $B n V Q$ genes were obtained by tandem and proximal duplications, respectively (Supplementary Table S2).

A total of $94 B n V Q$ s showed no intron (79.7\%), whereas only nine, five, and five $B n V Q$ s showed one, two, and three introns, respectively (Fig. 1; Supplementary Table S2). One and three $B n V Q$ genes had four and five introns, respectively. BnVQ15 had 14 introns (Fig. 1).

Further analysis indicated that most of the BnVQ proteins contained a conserved VQ motif (Fig. 2B). An alternate variant such as the VH motif was found in two BnVQs (BnVQ110: BnaC09g52630D; and BnVQ51: BnaA09g21180D) (Fig. 2B; Supplementary Table S2). Besides the core amino acid sequence, FXXXVQXLTG, a total of 17, six, and three BnVQs had FTG, VTG, and YTG, respectively (Fig. 2B). We found 10 other motifs in the BnVQ proteins, including five BnVQs of the PLN03210 superfamily (BnVQ76-BnaC03g72990D, BnVQ19-BnaA03g24930D, BnVQ50-BnaA09g20940D, BnVQ110-BnaC09g52630D, and BnVQ51-BnaA09g21180D), four BnVQs of the PHA03247 superfamily (BnVQ18-BnaA03g16140D, BnVQ66-BnaC02g32710D, BnVQ84-BnaC04g09870D, and BnVQ99-BnaC07g14570D), two BnVQs of the Calmodulin_bind superfamily (BnVQ110BnaC09g52630D and BnVQ51-BnaA09g21180D), and two BnVQs of the Cadherin $\mathrm{C}$ superfamily in BnVQ13 and BnVQ98 (BnaA03g54240D and BnaC07g46730D) (Fig. 1). Each of one of the BnVQ proteins was found in the STKc_GSK3 superfamily (BnVQ15-BnaA03g05700D), BgIB superfamily (BnVQ117BnaCnng66440D), Sema superfamily (BnVQ113-BnaAnng39520D), PRK13335 superfamily (BnVQ35-BnaA06g40350D), and flgJ superfamily (BnVQ100-BnaC07g19440D), respectively (Fig. 1). Among them, BnVQ110 and BnVQ51 contained both the PLN03210 and Calmodulin_bind superfamilies except the VQ motif.

Fifteen categories of $c i$-elements were identified in the promoter regions of $B n V Q$ genes, including 1,542 basic CAAT boxes (Supplementary Fig. S2). The first category distributed in promoter regions was "light responsiveness," which accounted for $21.1 \%$ $(1,090$ of 5,165$)$ of the total elements. Fourteen percent were hormone-responsive elements, such as 247 abscisic acid (ABA), 76 auxin, 60 gibberellin (GA), 350 methyl jasmonate (MeJA), and 30 salicylic acid (SA) responsiveness elements. A total of $674 \mathrm{MYB}$ and 294 MYC binding sites were identified in the promoter regions of Brassica napus $V Q$ genes; 188 drought-inducible elements and defense and stress-responsive elements were also obtained (Supplementary Fig. S2; Supplementary Table S3).

Evolutionary analysis of $V Q$ genes between Brassica napus and its ancestors. The protein sequences of $B n V Q$ genes, AtVQ genes, and their homologs in Brassica rapa and Brassica oleracea were used for phylogenetic tree analysis to understand the evolutionary relationships of VQ proteins. A total of $118 \mathrm{BnVQs}, 33$ AtVQs of Arabidopsis thaliana, 64 BoVQs of Brassica oleracea, and 56 BrVQs of Brassica rapa were applied to generate a phylogenetic tree. Brassica VQ proteins were divided into four 
groups, and a total of 16, 24, 16, and 62 BnVQs were classified into groups I, II, III, and IV, respectively (Fig. 2A). The collinear relationships of duplication pairs in the BnVQ family indicated that 166 paralogs were sharing higher identities with their protein sequences (Fig. 3A). We also identified enormous synteny blocks of Brassica napus subgenomes of $\mathrm{A}$ and $\mathrm{C}$ or between different chromosomes of $\mathrm{A}$ and $\mathrm{C}$. The identified paralog pairs were all located within syntenies on Brassica napus chromosomes (Fig. 3A).

Synteny analysis of VQ genes in the three Brassica genera (Brassica napus, Brassica rapa, and Brassica oleracea) and their common ancestor Arabidopsis thaliana showed strong collinearity even though the chromosomal rearrangements or gene duplication occurred between Brassica napus and ancestral species (Brassica rapa and Brassica oleracea) divergent from Arabidopsis thaliana (Fig. 3B). Using synteny analysis, we categorized four gene types, including novel genes that emerged in Brassica napus only; conserved genes that had a unique copy in four Brassica species; multicopy genes, which are presented as homologous genes in four species; and lost genes that were detected in the three other ancestral species but not in Brassica napus. Through a karyotype analysis of the $V Q$ genes in the Brassica genus, we identified 91 conserved and 90 multicopy $V Q$ genes in 27 groups and 27 novel and six lost $V Q$ genes in Brassica napus, respectively (Fig. 3B).

Identification of $B \boldsymbol{n V Q 7}$ encoding $B \boldsymbol{n M K S 1}$. Among the $B n V Q$ s, one (BnVQ7 [BnaA01g36880D]) was located in chromosome A01, which was characterized as a MAP kinase substrate gene MKS1. BnMKS1 has one exon including 218 amino acids, in which the estimated molecular weight was $22.86 \mathrm{kDa}$. The promoter region of BnMKS1 had 45 cis-acting elements, including 15 light responsiveness elements, two anaerobic induction elements, 11 hormone-related elements, one defense and stress responsiveness element, and one wound responsive element, demonstrating that $B n M K S 1$ plays an important function in plant defense signaling and pathogen resistance. There was a meristem-specific expression ciselement in the BnMKS1 gene.
Overexpressing BnMKS1 in Brassica napus transgenic lines display a semi-dwarf phenotype. To further understand the function of $B n M K S 1$, we overexpressed the gene in the Westar variety by inserting the full length of cDNA behind the CaMV 35S promoter. Kanamycin and PCR were used to screen the BnMKS1 transgenic lines. Two independent transgenic lines (OEBnMKS1-7 and OEBnMKS1-33) showing much higher expression of the $B n M K S 1$ gene than the wild-type control were selected and used for further studies from 31 positive $\mathrm{T}_{0}$ plants by qPCR analysis (Supplementary Fig. S3). Compared with wild-type plants, overexpressing BnMKS1 transgenic lines displayed a semi-dwarf phenotype in $\mathrm{T}_{0}$ plants (Fig. 4). We observed that both of the overexpressed transgenic canola lines grew shorter and smaller at the 2-week stage and later than the untransformed control.

Overexpressing BnMKS1 in Brassica napus transgenic lines did not enhance resistance to $L$. maculans at the seedling stage. To test the effect of the overexpressed BnMKS1 gene on resistance to blackleg disease in canola, we inoculated isolate JN3 onto the cotyledons of two $T_{0}$ transgenic lines (OEBnMKS1-7 and OEBnMKS1-33) and onto six lines of $\mathrm{T}_{2}$ plants from each of the overexpressed $T_{0}$ plants. There was no significant change in disease between the wild-type plants and transgenic lines, which means that the cotyledons of Westar and overexpressed $B n M K S 1$ plants still showed susceptible/compatible reaction to the L. maculans isolate. This was confirmed by the quantification of lesion sizes on wild-type and transgenic plants since the percentages of lesions on the cotyledons of seedlings did not show any significant variation in wild-type and both $\mathrm{T}_{0}$ and $\mathrm{T}_{2}$ plants of transgenic lines (Supplementary Fig. S4). Taken together, transgenic canola plants overexpressing BnMKS1 did not show enhanced resistance to blackleg disease at the seedling stage.

Overexpressing BnMKS1 in Brassica napus transgenic lines showed enhanced resistance to $L$. maculans in adult plants. Since BnMKS1 does not contribute to qualitative resistance against blackleg disease in canola, we investigated adult plant resistance in both wild-type and transgenic plants. The average
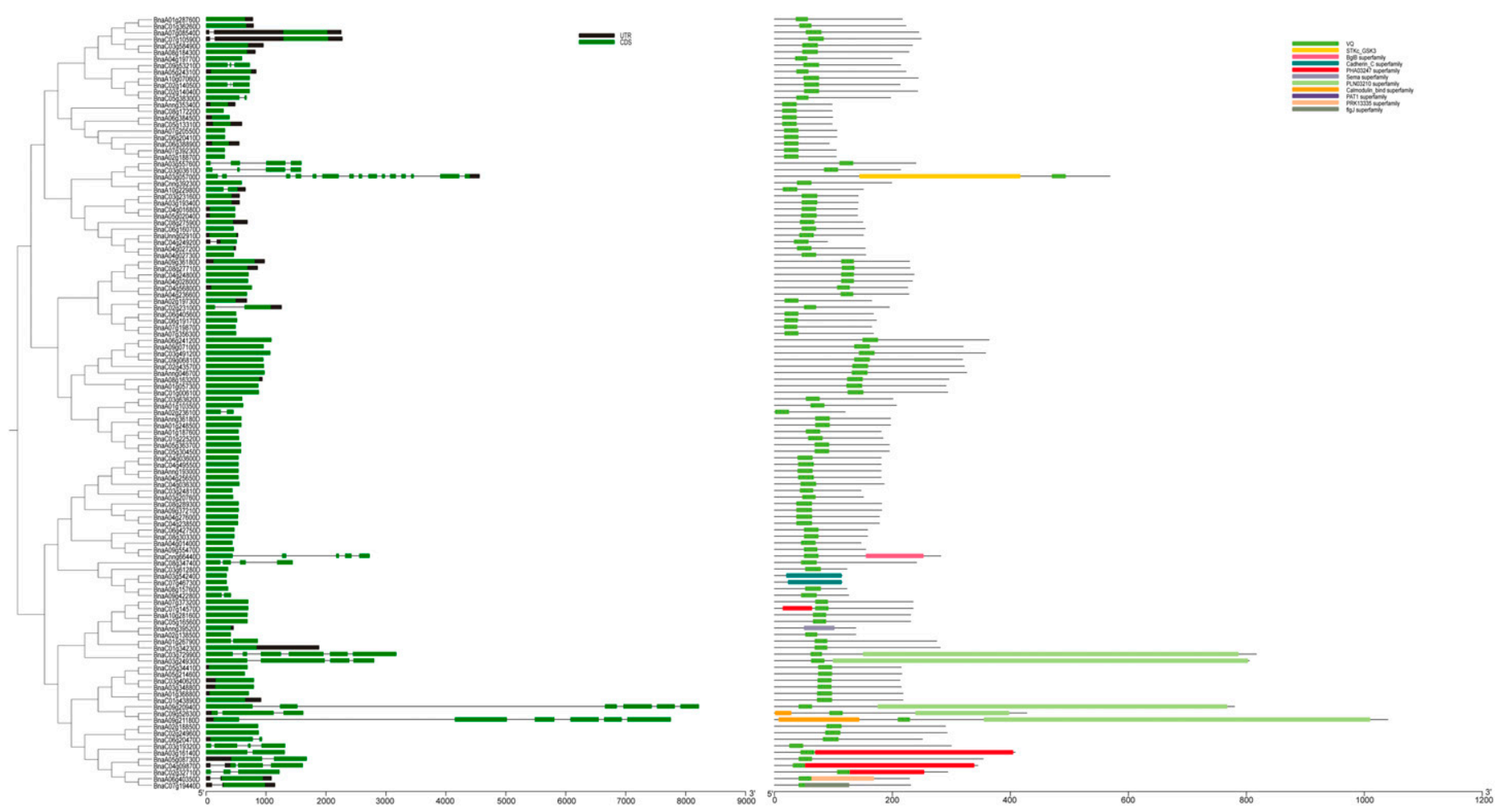

Fig. 1. Left, Intron and exon structure of the Brassica napus valine-glutamine motif (BnVQ) genes according to the phylogenetic relationships. The untranslated region (UTR) and exon are indicated as black and green boxes, respectively. The black lines denote introns. Right, Conserved domain analysis of BnVQs and predicted domains are represented by different colored boxes. CDS = coding sequence. 
disease rating scores in Westar $\mathrm{T}_{2}$ plants derived from OEBnMKS17 and OEBnMKS1-33 showing higher expression of BnMKS1 were $3.83,1.67$, and 2.16 , respectively (Fig. 5). We observed that there was less infection in the cross-section of canola stems in overexpressing BnMKS1 lines compared with the wild-type Westar plants (Fig. 5). This finding indicates that the Westar plant displayed susceptible reaction to the blackleg $L$. maculans isolate, whereas overexpressing BnMKS1 lines showed resistance to blackleg disease; therefore, the transgenic canola lines with the overexpressed BnMKS1 gene showed enhanced resistance to blackleg disease in adult plants.
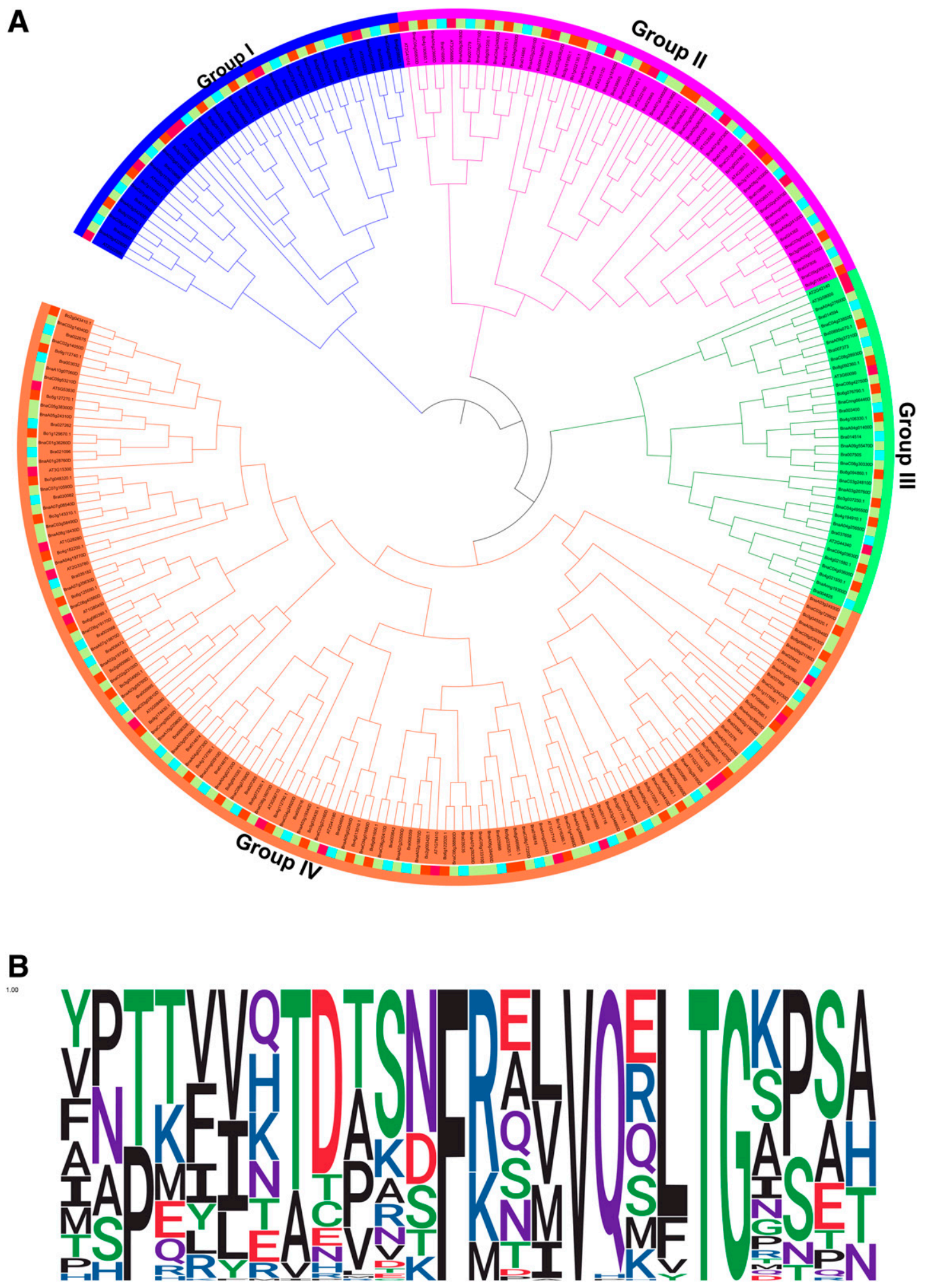

Fig. 2. A, Phylogenetic tree of valine-glutamine motif (VQ) proteins from Arabidopsis thaliana, Brassica rapa, Brassica oleracea, and Brassica napus. The VQs were divided into four groups (groups I to IV) based on the clustering of the protein sequence. Proteins from Arabidopsis thaliana, Brassica rapa, Brassica oleracea, and Brassica napus are colored in red, light blue, light red, and yellow, respectively. B, Distribution of the BnVQ conserved motifs in Brassica napus. MEME motifs are stacked by letters at each investigated site. The $x$-axis represents the width of the motif, whereas the $y$-axis represents the frequency of each letter. 
Expression analysis of downstream genes of BnMKS1. Based on the disease progression in cotyledons, eight downstream genes, including Brassica napus phytoalexin deficient 3 (BnPAD3), BnCYP71A13 (cytochrome P450, family 71, subfamily A, polypeptide 13), BnNUDT6 (nudix hydrolase homolog 6), BnROF2 (FK506 binding protein 65), BnPR2 (pathogenesis related: $\beta-1,3-$ glucanase), BnPR3 (pathogenesis related: chitinases), BnPR5 (pathogenesis related: thaumatin like), and BnPDF1.2 (plant defensin 1.2), were included for gene expression analysis in both Westar and the OEBnMKS1 line (OEBnMKS1-7) inoculated with L. maculans isolate JN3 at biotrophic and necrotrophic stages (7 and 11 dpi) (Haddadi et al. 2016; Sonah et al. 2016). The transcript abundance of $B n P A D 3$ was elevated in the overexpression of the $B n M K S 1$ transgenic line. There was a slight increase in BnPAD3
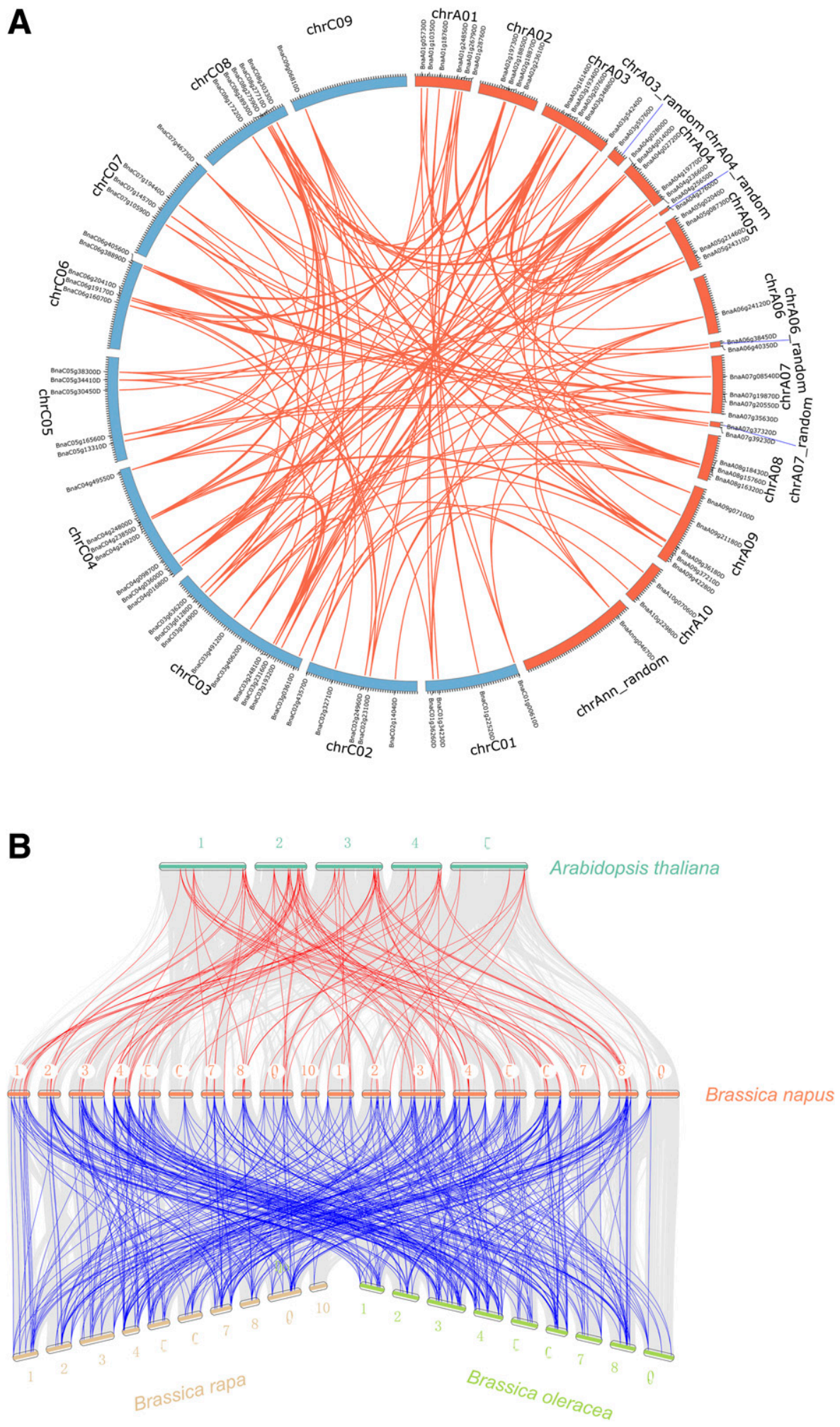

Fig. 3. A, Collinear gene pairs of Brassica napus valine-glutamine motif (BnVQ) genes on 21 Brassica napus chromosomes (chrs) are indicated as red lines in the circled plot. B, Synteny map of orthologous relationships between $V Q$ s in Arabidopsis thaliana, Brassica rapa, Brassica oleracea, and Brassica napus. VQ genes are plotted against their predicted counterparts in the four species. 
expression in the Westar plant from 7 to $11 \mathrm{dpi}$; however, expression of $B n P A D 3$ significantly increased in the overexpression line at 11 dpi (Fig. 6). There was no expression of BnCYP71A13 in Westar plants at both 7 and $11 \mathrm{dpi}$ when inoculated with $L$. maculans isolate JN3; however, the expression level of BnCYP71A13 was significantly increased in the OEBnMKS1 line, especially at $11 \mathrm{dpi}$
(Fig. 6). Interestingly, the transcripts of BnNUDT6 and BnROF2 were only enriched in the OEBnMKSI line at 11 dpi (Fig. 6). The expression levels of $B n P R 3$ and $B n P R 5$ had significant increases in the overexpression line at $11 \mathrm{dpi}$, whereas there was no obvious change in Westar plants (Fig. 6). BnPR2 transcription in the overexpression line was higher than that in Westar and it increased
A
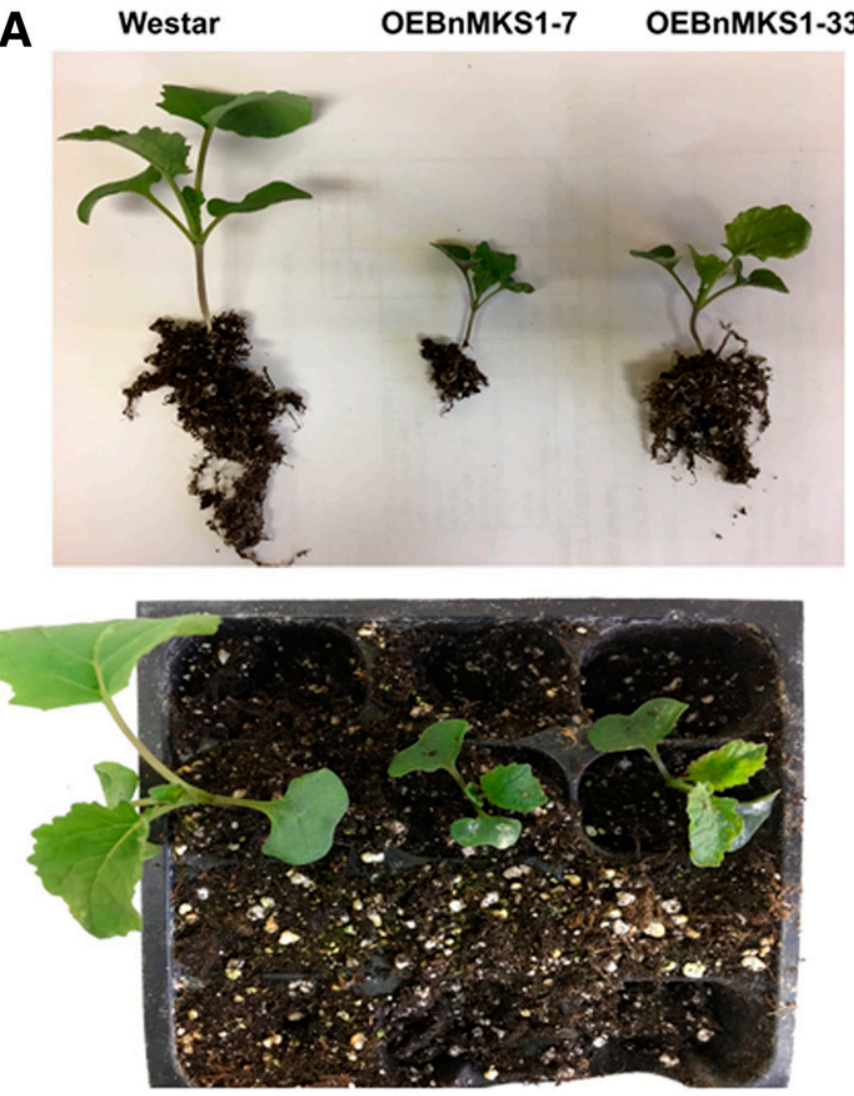

B
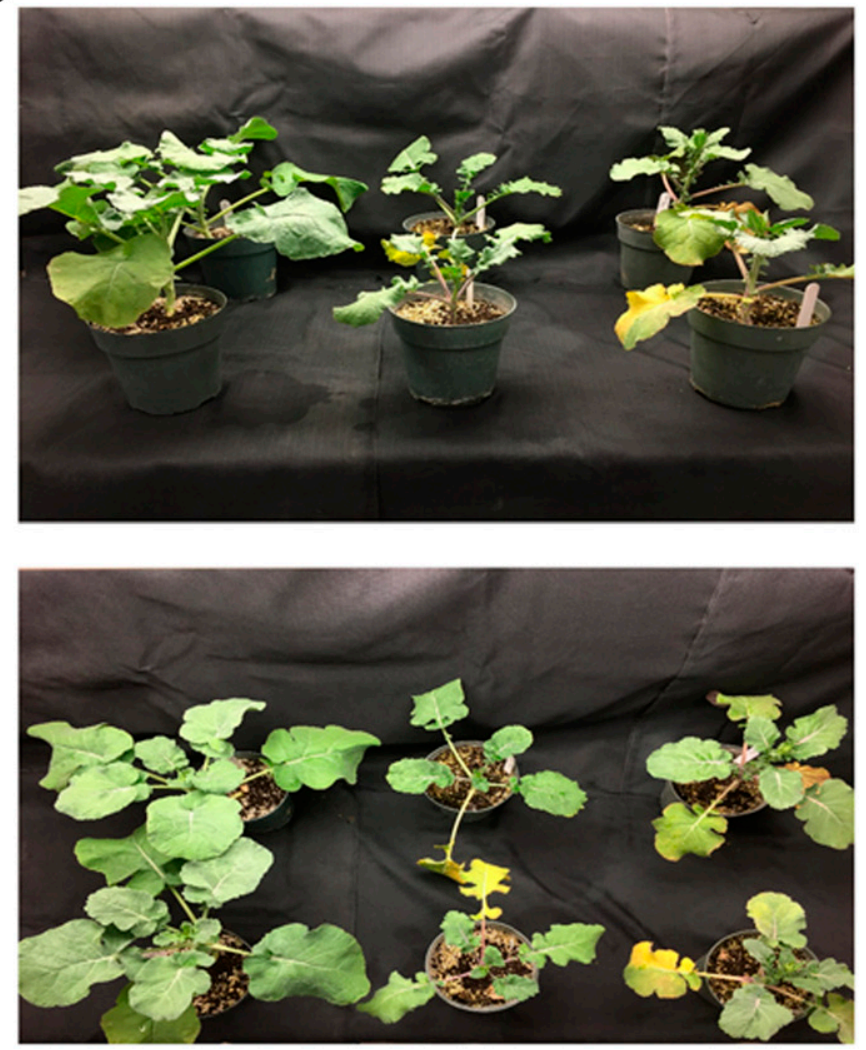

Fig. 4. Phenotype of wild-type (Brassica napus 'Westar') and two transgenic overexpressing mitogen-activated protein kinase 4 substrate 1 (MKS1) canola $\mathrm{T}_{0}$ lines (OEBnMKS1-7 and OEBnMKS1-33) at $\mathbf{A}, 2$ weeks and $\mathbf{B}, 1$ month, respectively.

A

Westa

OEBnMKS1-7
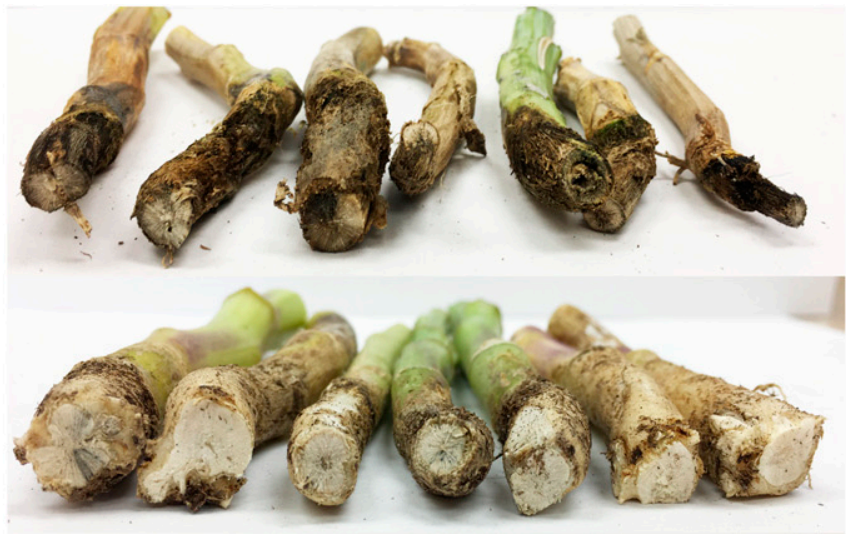

OEBnMKS1-33

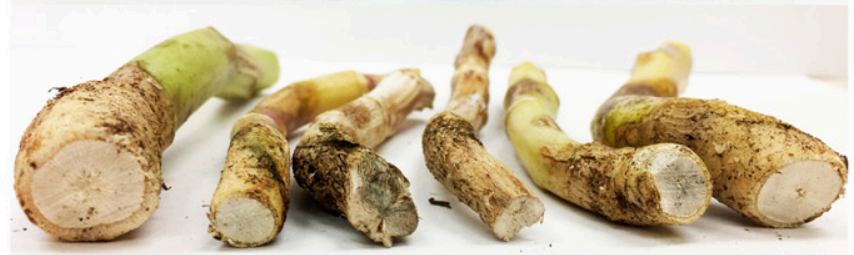

B

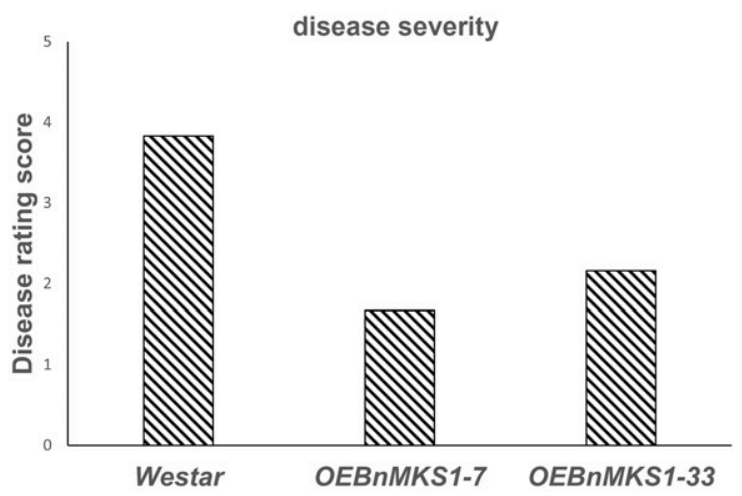

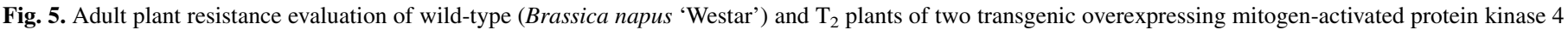

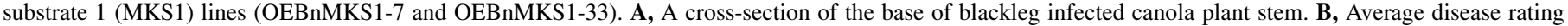
scores. Plants were harvested and rated after maturing. 
significantly at $11 \mathrm{dpi}$ in the OEBnMKS1 plant. BnPDF1.2, one of the plant defense marker genes, showed higher expression in Westar at $7 \mathrm{dpi}$ but increased slightly at $11 \mathrm{dpi}$. By contrast, BnPDF1.2 expressed a lower level at $7 \mathrm{dpi}$ but displayed a significant increase of transcripts in the OEBnMKS1 line at $11 \mathrm{dpi}$ (Fig. 6).

\section{DISCUSSION}

In this study, we identified the $V Q$ gene family from the published genome sequences of Brassica napus. The comprehensive analysis of $B n V Q$ genes, including chromosomal localization, phylogenetic relations, collinearity, gene structure, and promoter, was investigated. Overexpression of $B n V Q 7$ (reported as $B n M K S 1$ ) enhanced plant resistance to blackleg disease in adult canola plants. We also analyzed the expression patterns of BnMKS1 downstream genes. We hope that the understanding of $B n V Q$ genes and their function in resistance to blackleg disease provided in this study will facilitate understanding of the mechanisms of plant growth and development and canola disease resistance.

Blackleg disease is one of the most important diseases in canola/ oilseed rape (Brassica napus) in Canada, Australia, and Europe, which causes significant yield loss yearly. This disease is mainly caused by the aggressive species $L$. maculans and less aggressive Leptosphaeria biglobosa. There are two types of resistance for the canola plant against blackleg disease. First, qualitative resistance is controlled by major $(R)$ genes. Eighteen $R$ genes have been identified from different Brassica species such as Brassica napus, Brassica juncea, or Brassica rapa (Delourme et al. 2006; Raman et al. 2013). Adult plant resistance conferred by multiple minor/ quantitative resistance genes or loci is considered more durable toward blackleg resistance in canola. $R$ gene resistance is effective against the fungal population with the corresponding avirulence gene; however, the selection pressure generated from the pathogen population in canola fields can cause a breakdown of $R$ gene resistance (Marcroft et al. 2012; Rouxel et al. 2003; Sprague et al. 2006; Van de Wouw et al. 2010; Zhang et al. 2016). On the other hand, adult plant resistance is more durable and can supplement $R$ gene resistance as an effective strategy for the management of blackleg disease. Then, understanding minor gene effects on blackleg disease resistance is also important to decrease disease incidence/severity and reduce yield loss. Overexpression of $B n V Q 7$ (BnaA01g36880D, also known as MKS1) did not alter disease symptoms and resistance at the seedling stage by cotyledon inoculation; however, it significantly enhanced resistance to blackleg disease in the susceptible canola variety Westar. These results showed that the Brassica napus $V Q$ genes cannot function as an $R$ gene at the seedling stage but may play important roles in adult plant disease resistance.

The VQ-WRKY partnership was extensively studied in Arabidopsis thaliana, which indicates that the interaction of the VQ protein with different WRKYs can trigger the defense response (Jing and Lin 2015). Other studies demonstrated that VQ proteins are involved in the SA- and/or jasmonic acid (JA)-mediated defense response. For example, overexpressed $V Q 23$ lines showed reduced disease symptoms after infection with both Pseudomonas syringae and Botrytis cinerea. In addition, the VQ23 overexpression line displays enhanced resistance to Botrytis cinerea depending on a functional WRKY33. It is likely that VQ23 positively mediates the plant defense to necrotrophic and biotrophic pathogens through a WRKY-dependent signaling pathway (Jing and Lin 2015; Lai et al. 2011; Xie et al. 2010). VQ21 (MKS1) is reported as the substrate of MPK4 and links MPK4 kinase to WRKY33 by interacting with both proteins. Then, WRKY33 binds to the promoter of $P A D 3$ to trigger the plant defense response (Andreasson et al. 2005; Qiu et al. 2008). Previous studies also suggested that $V Q 21 / M K S 1$ was involved in a positive role in the SA-mediated defense response against biotrophic pathogens but a negative role in the JA-regulated defense response to necrotrophic pathogens (Fiil and Petersen 2011; Petersen et al. 2010). In Brassica napus, Wang et al. (2009, 2015) also confirmed that BnMKS1 could interact with both BnWRKY33 and BnMPK4. Consequently, they were substantially and synergistically expressed in response to $S$. sclerotiorum infection; therefore, overexpression of BnWRKY33 and BnMPK4 lines enhances resistance to Sclerotinia disease in oilseed rape. In this
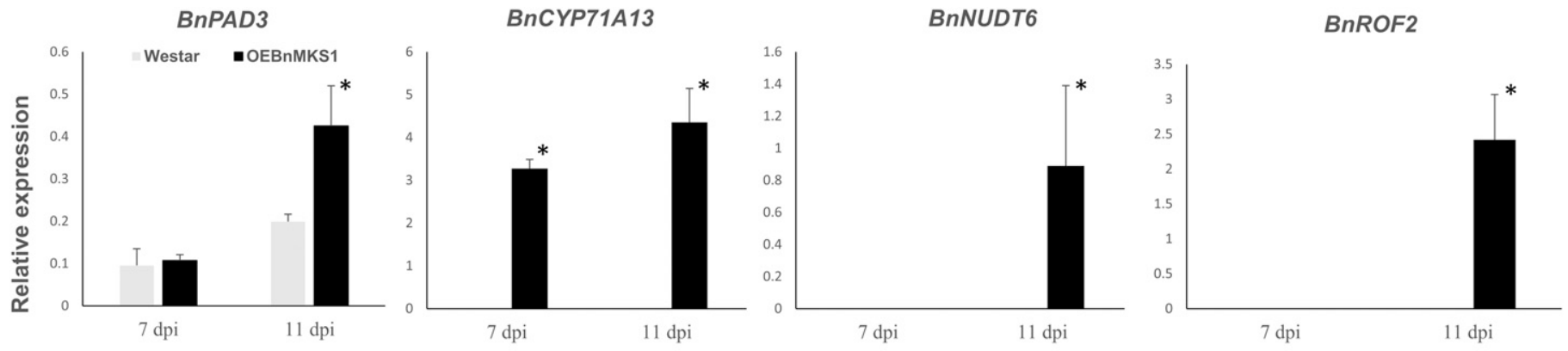

BnPR3

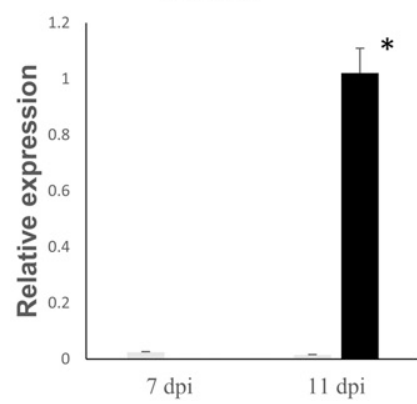

BnPR5

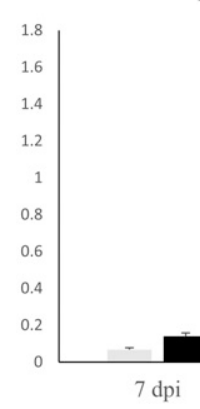

BnPR2

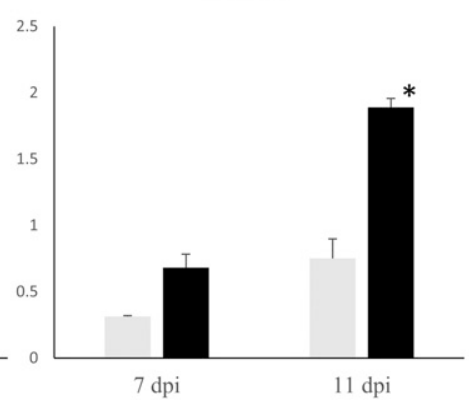

BnPDF1.2

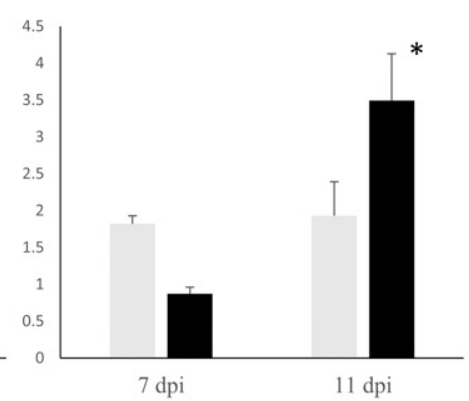

Fig. 6. Real-time PCR quantitation of Phytoalexin deficient 3 (PAD3), CYP71A13 (cytochrome P450, family 71, subfamily A, polypeptide 13), NUDT6 (nudix hydrolase homolog 6), ROF2 (FK506 binding protein 65), PR2 (pathogenesis related: $\beta$-1, 3 -glucanase), PR3 (pathogenesis related: chitinases), PR5 (pathogenesis related: thaumatin like), and $P D F 1.2$ (plant defensin 1.2). Expression analysis in the wild type and the overexpressing mitogen-activated protein kinase 4 substrate 1 (MKS1) line with the highest transcripts level (OEBnMKS1-7) inoculated by Leptosphaeria maculans at 7 and 11 days postinoculation (dpi). Means \pm standard deviations are indicated above bars. * indicates that the transcription abundance varies significantly compared with the control plant $(P<0.05)$. 
study, overexpression of BnMKS1 in the transgenic line enhances resistance to L. maculans, which was the first report to characterize the function of the Brassica napus VQ gene. L. maculans is considered a hemibiotrophic fungal pathogen, which stays in the biotrophic and necrotrophic stages on canola cotyledons at 7 and 11 dpi, respectively (Fitt et al. 2006; Haddadi et al. 2016; Sonah et al. 2016). We observed that the $B n M K S 1$ overexpression line showed increased expression of $P R 2$ and $P R 5$ at both biotrophic (7 dpi) and necrotrophic stages (11 dpi), suggesting that the SA signaling pathway was activated, especially at the necrotrophic stage of L. maculans infection. Thus, the accumulation of SA marker proteins leads the plant to obtain a systemic acquired resistance. Expression of $P R 3$ and PDF1.2 in the $B n M K S 1$ overexpression transgenic line was lower at the biotrophic stage (7 dpi) but significantly increased and was higher than that of the control plants at the necrotrophic stage of $L$. maculans infection, indicating the activation of the JA signaling pathway to obtain the local acquired resistance. This observation is consistent with the finding that necrotrophic pathogens induce JA signaling and the activation of JA marker genes including PR3, PR4, and PRI2 in Brassica juncea (Ali et al. 2017). Wang et al. (2012a) also reported that both SA- and JA-mediated pathways were involved in defense responses to S. sclerotiorum in Brassica napus. In conclusion, the SA- and JAmediated signaling pathways are both involved in the defense response to L. maculans infection in Brassica napus.

Since BnMKS1 interacts with both BnWRKY33 and BnMPK4, we also investigated the expression of downstream genes of WRKY33, including PAD3, CYP71A13, NUDT6, and ROF2, in this study (Fiil and Petersen 2011; Petersen et al. 2008; Qiu et al. 2008). BnNUDT6 and BnROF2 expressions only seem to be induced in dependence of BnMKS1 in Brassica napus challenged by L. maculans at the necrotrophic stage. The necrotrophic pathogen Botrytis cinerea induced similar expression patterns of $P A D 3$ and CYP71A13 genes in both wild-type and 35S-MKS1 Arabidopsis plants. This indicates that $M K S 1$ utilized other mechanisms to control the 35S-MKS1 susceptibility (Fiil and Petersen 2011); however, in this study, we found that the hemibiotrophic pathogen L. maculans significantly enhanced expression of BnCYP71A13 in the OEBnMKS1 transgenic line but not in wild-type plants, suggesting that the dependence of $B n C Y P 71 A 13$ expression in OEBnMKS1 may play important roles in deference to blackleg disease. Similar expression levels of BnPAD3 in the Westar variety and the OEBnMKS1 line were observed at the biotrophic stage of L. maculans infection, indicating that BnMKS1 cannot induce expression of $B n P A D 3$ against a pathogen at the biotrophic stage. By contrast, $B n P A D 3$ probably plays important roles in the defense response to the $L$. maculans pathogen at the necrotrophic stage, since the abundance of transcription increased significantly in the OEBnMKS1 transgenic line. Another possibility is that other proteins, such as WRKY25 and MPK11 that also interact with MKS1, may comprise and be involved in the resistance to fungal pathogens (Andreasson et al. 2005; Cheng et al. 2012; Pecher et al. 2014; Petersen et al. 2010). Further studies are required to understand why the expression patterns of these four downstream genes in Brassica napus induced by a hemibiotrophic fungal pathogen are different from dependent or independent expression in 35S-MKS1 in Arabidopsis thaliana. For example, the involvement of BnWRKY33 and $B n M P K 4$ in the defense responses against biotrophic, necrotrophic, or hemibiotrophic pathogens and their effects on expression of $B n M K S 1$ should be further studied and discussed.

In plant immunity systems, two models were proposed: pathogen-associated molecular pattern-triggered immunity (PTI) and effector-triggered immunity (ETI). Pathogen-associated molecular patterns consist of microbial and pathogen structures and are recognized by plant recognition receptors (i.e., pattern recognition receptor proteins). Then PTI is activated to produce an immune response against pathogen infection (Ali et al. 2018). On the other hand, a fungal pathogen (e.g., L. maculans) can secrete effector proteins (Avr) that interact with or are recognized by resistance proteins ( $\mathrm{R}$ in Brassica napus) and then induce the defense response (ETI). Westar is a susceptible canola variety, which has none of the identified resistance genes $(R)$. Overexpression of BnMKS1 in Westar plants showed enhanced resistance to L. maculans infection, providing the first insight into the function of Brassica napus $V Q$ in the PTI system. In the future, it will be interesting to investigate $B n M K S 1$ function in both PTI and ETI systems in canola plants that have the blackleg $R$ gene. Besides the functions in plant defense responses, $V Q$ genes also play various roles in plant growth and development; for example, AtVQ14/IKU1 regulates endosperm growth and seed size in Arabidopsis plants (Wang et al. 2010), and AtVQ29 causes hyposensitivity in hypocotyl growth and elongation in different light sources ( $\mathrm{Li}$ et al. 2014a, b). Interestingly, overexpression of AtVQ21/MKS1 plants showed a semi-dwarfed phenotype in Arabidopsis plants (Andreasson et al. 2005). A similar semi-dwarfed plant growth phenotype was found in overexpression of $V Q 17, V Q 18$, and VQ22 in Arabidopsis plants (Cheng et al. 2012). In this study, we also observed the semi-dwarf phenotype in Brassica napus transgenic plants overexpressing $B n M K S 1$, suggesting that $B n M K S 1$ maintained a similar function from Arabidopsis thaliana VQ21/MKS1. In summary, these findings indicate that $B n V Q 7 / B n M K S 1$ plays an important function not only in response to pathogen infection but also in canola plant growth and development. The identification of Brassica napus $V Q$ genes will provide a foundation for further studies on the biological functions of BnVQ proteins against biotic and abiotic stresses.

In this study, $118 V Q$ genes were identified from the Brassica napus genome, which was over three times the $V Q$ gene number $(n=$ 34 ) in Arabidopsis thaliana. A previous report indicated that there were $57 V Q \mathrm{~s}$ in Brassica rapa (A genome), which has experienced a whole-genome triplication from its ancestor Arabidopsis thaliana (Zhang et al. 2015). We have to note that the number of $B r V Q \mathrm{~s}$ is expected to be $>100$ because the whole-genome triplication occurred in the evolution process from Arabidopsis thaliana; however, there are only 57 identified $B r V Q$ genes in Brassica rapa, which indicates that extensive gene loss occurred during genome duplication (Cheng et al. 2013; Wang et al. 2011). Similarly, we found $64 V Q$ genes in Brassica oleracea (C genome), suggesting that gene loss occurred during evolution as well. As is well known by U's triangle, Brassica napus is an allotetraploid with the AACC genome derived from a combination of the two diploid genomes of Brassica rapa (AA genome) and Brassica oleracea (CC genome) (Nagaharu 1935); therefore, the number of $V Q$ genes found in Brassica napus $(n=118)$ was almost the same as the total number of $V Q$ genes detected from the two ancestral species, including 57 in Brassica rapa and 64 in Brassica oleracea. Taken together, these results suggest that extensive gene loss occurred in Brassica napus since the hybridization of Brassica rapa and Brassica oleracea diverged from the duplication from the common ancestor Arabidopsis thaliana. Genome duplication usually expands the genome content and diversifies the gene function (Liu et al. 2014). Gene duplication can drive the genes to form silenced function, partitioned function, and/or a new function (Barker et al. 2012; Krishnamurthy et al. 2015; Zhang 2003). Thus, understanding the $V Q$ gene duplication models and their collinearity and synteny relationships among the close species is valuable. WGD or segmental duplication mainly caused the expansion of the $B n V Q$ gene family ( 105 of $118 ; 89.0 \%$ ), whereas few others were produced by dispersed duplication ( 10 of $118 ; 8.5 \%)$, tandem duplication ( 2 of $118 ; 1.7 \%$ ), and proximal duplication (1 of $118 ; 0.8 \%$ ). This result is consistent with previous reports that high segmental and low tandem duplication ratios were detected in Brassica rapa and Arabidopsis thaliana for the expansion of the gene superfamily (Cannon et al. 2004; Krishnamurthy et al. 2015). It is important to know that segmental duplication or WGD is one of the main reasons to maintain the gene family (Cannon et al. 2004). Thus, the majority of segmental duplication that occurred in $B n V Q$ genes caused them to retain a similar function in Brassica napus to their homologs in Arabidopsis thaliana. The $V Q$ gene duplication that occurred in 
Brassica napus was similar to the identified transcription factors, such as BnAP2/EREBPs and BnMYBs (Wang et al. 2018).

Usually, the core amino acids $\mathrm{V}$ and $\mathrm{Q}$ are conserved in plant species, such as in Arabidopsis thaliana, Brassica rapa, or grape (Vitis vinifera), and there are no other variants in VQ motifs (Cheng et al. 2012; Wang et al. 2015; Zhang et al. 2015). The alternative VH amino acids found in two Brassica napus VQ are another example that shows how the VQ domain could be replaced by VH. Kim et al. (2013) reported that there are two VQ proteins, OsVQ37 and OsVQ39, that have the VH domain in rice as well. By contrast, the ending of VQ motif sequences such as VTG, FTG, or LTG was commonly found in the VQ proteins identified from different plant species. Besides the light-responsiveness elements detected in Brassica napus VQ proteins, the most abundant cis-element category identified in the promoter regions was hormoneresponsive elements, including ABA, SA, GA, auxin, and MeJA. The cis-elements involved in SA, JA, and MeJA were reported to play critical roles in plant signaling transduction for defending against biotic and abiotic stresses (Gaffney et al. 1993; Xu et al. 1994). Thus, most of the identified $B n V Q$ s in this study may be involved in plant defenses against fungal pathogens. We identified many cis-elements related to drought and stress responses or transcription factors in Brassica napus VQs, which are also similar to the cis-elements reported in promoter regions from other plant species. Thus, $B n V Q$ genes express and provide a certain function in response to abiotic/environmental stimuli. The diversified ciselement types in the promoter regions of $B n V Q$ s indicated that they might display a wide range of functions. For example, gene expression analysis indicated that some of the rice $V Q$ genes were coexpressed with WRKY transcription factors in the defense against three different pathogens ( Li et al. 2014a, b; Wang et al. 2015). Song et al. (2016) reported that $27 \mathrm{ZmVQ}$ genes were coexpressed with 49 $Z m W R K Y$ transcription factors under drought stress. Grape $V Q$ genes exhibited altered expression patterns in response to drought, powdery mildew infection, SA, and ethylene treatment and showed significant correlations with WRKY transcription factors (Wang et al. 2015). The results of the gene structure and promoter analysis show that it is worth exploring the functions of $B n V Q$ genes and their responses to various biotic and abiotic stresses in Brassica napus.

\section{LITERATURE CITED}

Ali, S., Ganai, B. A., Kamili, A. N., Bhat, A. A., Mir, Z. A., Bhat, J. A., Tyagi, A., Islam, S. T., Mushtaq, M., Yadav, P., Rawat, S., and Grover, A. 2018. Pathogenesis-related proteins and peptides as promising tools for engineering plants with multiple stress tolerance. Microbiol. Res. 212-213: 29-37.

Ali, S., Mir, Z. A., Bhat, J. A., Chandrashekar, N., Papolu, P. K., Rawat, S., and Grover, A. 2017. Identification and comparative analysis of Brassica juncea pathogenesis-related genes in response to hormonal, biotic and abiotic stresses. Acta Physiol. Plant. 39:268.

Altschul, S. F., Madden, T. L., Schäffer, A. A., Zhang, J., Zhang, Z., Miller, W., and Lipman, D. J. 1997. Gapped BLAST and PSI-BLAST: A new generation of protein database search programs. Nucleic Acids Res. 25: 3389-3402.

Andreasson, E., Jenkins, T., Brodersen, P., Thorgrimsen, S., Petersen, N. H., Zhu, S., Qiu, J., Micheelsen, P., Rocher, A., Petersen, M., Micheelsen, P., Rocher, A., Petersen, M., Newman, A., Nielsen, H. B., Hirt, H., Somssich, I., Mattsson, O., and Mundy, J. 2005. The MAP kinase substrate MKS1 is a regulator of plant defense responses. EMBO J. 24:2579-2589.

Ansan-Melayah, D., Rouxel, T., Bertrandy, J., Letarnec, B., Mendes-Pereira, E., and Balesdent, M. H. 1997. Field efficiency of Brassica napus specific resistance correlates with Leptosphaeria maculans population structure. Eur. J. Plant Pathol. 103:835-841.

Balesdent, M. H., Attard, A., Kuhn, M. L., and Rouxel, T. 2002. New avirulence genes in the phytopathogenic fungus Leptosphaeria maculans. Phytopathology 92:1122-1133.

Barker, M. S., Baute, G. J., and Liu, S. L. 2012. Duplications and turnover in plant genomes. Plant Genome Divers. 1:155-169.

Cannon, S. B., Mitra, A., Baumgarten, A., Young, N. D., and May, G. 2004. The roles of segmental and tandem gene duplication in the evolution of large gene families in Arabidopsis thaliana. BMC Plant Biol. 4:10.
Canola Council of Canada. 2020. Canola production. https://www.canolacouncil.org/about-canola/industry/

Chalhoub, B., Denoeud, F., Liu, S., Parkin, I. A., Tang, H., Wang, X., Chiquet, J., Belcram, H., Tong, C., Samans, B., Corréa, M., Da Silva, C., Just, J., Falentin, C., Koh, C. S., Le Clainche, I., Bernard, M., Bento, P., Noel, B., Labadie, K., Alberti, A., Charles, M., Arnaud, D., Guo, H., Daviaud, C., Alamery, S., Jabbari, K., Zhao, M., Edger, P. P., Chelaifa, H., Tack, D., Lassalle, G., Mestiri, I., Schnel, N., Le Paslier, M. C., Fan, G., Renault, V., Bayer, P. E., Golicz, A. A., Manoli, S., Lee, T. H., Thi, V. H., Chalabi, S., Hu, Q., Fan, C., Tollenaere, R., Lu, Y., Battail, C., Shen, J., Sidebottom, C. H., Wang, X., Canaguier, A., Chauveau, A., Bérard, A., Deniot, G., Guan, M., Liu, Z., Sun, F., Lim, Y. P., Lyons, E., Town, C. D., Bancroft, I., Wang, X., Meng, J., Ma, J., Pires, J. C., King, G. J., Brunel, D., Delourme, R., Renard, M., Aury, J. M., Adams, K. L., Batley, J., Snowdon, R. J., Tost, J., Edwards, D., Zhou, Y., Hua, W., Sharpe, A. G., Paterson, A. H., Guan, C., and Wincker, P. 2014. Early allopolyploid evolution in the postNeolithic Brassica napus oilseed genome. Science 345:950-953.

Chen, C., Xia, R., Chen, H., and He, Y. 2018. TBtools, a toolkit for biologists integrating various HTS-data handling tools with a user-friendly interface. bioRxiv 289660.

Cheng, F., Mandáková, T., Wu, J., Xie, Q., Lysak, M. A., and Wang, X. 2013. Deciphering the diploid ancestral genome of the mesohexaploid Brassica rapa. Plant Cell 25:1541-1554.

Cheng, Y., Zhou, Y., Yang, Y., Chi, Y. J., Zhou, J., Chen, J. Y., Wang, F., Fan, B., Shi, K., Zhou, Y. H., Yu, J., and Chen, Z. 2012. Structural and functional analysis of VQ motif-containing proteins in Arabidopsis as interacting proteins of WRKY transcription factors. Plant Physiol. 159:810-825.

Chi, Y., Yang, Y., Zhou, Y., Zhou, J., Fan, B., Yu, J., and Chen, Z. 2013. Protein-protein interactions in the regulation of WRKY transcription factors. Mol. Plant 6:287-300.

De Block, M., De Brouwer, D., and Tenning, P. 1989. Transformation of Brassica napus and Brassica oleracea using Agrobacterium tumefaciens and the expression of the bar and neo genes in the transgenic plants. Plant Physiol. 91:694-701.

Delourme, R., Chèvre, A. M., Brun, H., Rouxel, T., Balesdent, M. H., Dias, J. S., Salisbury, P., Renard, M., and Rimmer, S. R. 2006. Major gene and polygenic resistance to Leptosphaeria maculans in oilseed rape (Brassica napus). Eur. J. Plant Pathol. 114:41-52.

Fernando, W. G. D., Zhang, X., Selin, C., Zou, Z., Liban, S. H., McLaren, D. L., Kubinec, A., Parks, P. S., Rashid, M. H., Padmathilake, K. R., Rong, L., Yang, C., Gnanesh, B. N., and Huang, S. 2016. A six-year investigation of the dynamics of avirulence allele profiles, blackleg incidence, and mating type alleles of Leptosphaeria maculans population associated with canola crops in Manitoba, Canada. Plant Dis. 102:4.

Fiil, B. K., and Petersen, M. 2011. Constitutive expression of MKS1 confers susceptibility to Botrytis cinerea infection independent of PAD3 expression. Plant Signal. Behav. 6:1425-1427.

Fitt, B. D. L., Brun, H., Barbetti, M. J., and Rimmer, S. R. 2006. World-wide importance of Phoma stem canker (Leptosphaeria maculans and L. biglobosa) on oilseed rape (Brassica napus). Eur. J. Plant Pathol. 114: 3-15.

Gaffney, T., Friedrich, L., Vernooij, B., Negrotto, D., Nye, G., Uknes, S., Ward, E., Kessmann, H., and Ryals, J. 1993. Requirement of salicylic acid for the induction of systemic acquired resistance. Science 261:754-756.

Gunstone, F. D. 2011. Supplies of vegetable oils for non-food purposes. Eur. J. Lipid Sci. Technol. 113:3-7.

Guo, P., Wen, J., Yang, J., Ke, Y., Wang, M., Liu, M., Ran, F., Wu, Y., Li, P., $\mathrm{Li}$, J., and Fu, H. 2019. Genome-wide survey and expression analyses of the GRAS gene family in Brassica napus reveals their roles in root development and stress response. Planta 250:1051-1072.

Haddadi, P., Ma, L., Wang, H., and Borhan, M. H. 2016. Genome-wide transcriptomic analyses provides insights into the lifestyle transition and effector repertoire of Leptosphaeria maculans during the colonization of Brassica napus seedlings. Mol. Plant Pathol. 17:1196-1210.

Hu, Y., Chen, L., Wang, H., Zhang, L., Wang, F., and Yu, D. 2013. Arabidopsis transcription factor WRKY8 functions antagonistically with its interacting partner $V Q 9$ to modulate salinity stress tolerance. Plant J. 74:730-745.

Jiang, S., Sevugan, M., and Ramachandran, S. 2018. Valine-glutamine (VQ) motif coding genes are ancient and non-plant-specific with comprehensive expression regulation by various biotic and abiotic stresses. BMC Genomics 19:342.

Jiang, Y., and Yu, D. 2016. The WRKY57 transcription factor affects the expression of jasmonate ZIM-domain genes transcriptionally to compromise Botrytis cinerea resistance. Plant Physiol. 171:2771-2782.

Jing, Y., and Lin, R. 2015. VQ motif-containing protein family of plantspecific transcriptional regulators. Plant Physiol. 169:371-378.

Kim, D. Y., Kwon, S. I., Choi, C., Lee, H., Ahn, I., Park, S. R., Bae, S. C., Lee, S. C., and Hwang, D. J. 2013. Expression analysis of rice $V Q$ genes in response to biotic and abiotic stresses. Gene 529:208-214. 
Krishnamurthy, P., Hong, J. K., Kim, J. A., Jeong, M. J., Lee, Y. H., and Lee, S. L. 2015. Genome-wide analysis of the expansin gene superfamily reveals Brassica rapa-specific evolutionary dynamics upon whole genome triplication. Mol. Genet. Genomics 290:521-530.

Lai, Z., Li, Y., Wang, F., Cheng, Y., Fan, B., Yu, J., and Chen, Z. 2011. Arabidopsis sigma factor binding proteins are activators of the WRKY33 transcription factor in plant defense. Plant Cell 23:3824-3841.

Li, N., Li, X., Xiao, J., and Wang, S. 2014b. Comprehensive analysis of VQ motif-containing gene expression in rice defense responses to three pathogens. Plant Cell Rep. 33:1493-1505.

Li, Y., Jing, Y., Li, J., Xu, G., and Lin, R. 2014a. Arabidopsis VQ MOTIFCONTAINING PROTEIN29 represses seedling deetiolation by interacting with PHYTOCHROME-INTERACTING FACTOR1. Plant Physiol. 164: 2068-2080.

Liang, Z., Li, M., Liu, Z., and Wang, J. 2019. Genome-wide identification and characterization of the Hsp70 gene family in allopolyploid rapeseed (Brassica napus L.) compared with its diploid progenitors. PeerJ 7:e7511.

Liu, F., Li, X., Wang, M., Wen, J., Yi, B., Shen, J., Ma, C., Fu, T., and Tu, J. 2018b. Interaction of WRKY15 and WRKY33 transcription factors and their roles in the resistance of oilseed rape to Sclerotinia infection. Plant Biotechnol. J. 16:911-925.

Liu, P., Zhang, C., Ma, J., Zhang, L., Yang, B., Tang, X., Huang, L., Zhou, X., Lu, K., and Li, J. 2018a. Genome-wide identification and expression profiling of cytokinin oxidase/dehydrogenase $(C K X)$ genes reveal likely roles in pod development and stress responses in oilseed rape (Brassica napus L.). Genes (Basel) 9:168.

Liu, Z., Zhang, M., Kong, L., Lv, Y., Zou, M., Lu, G., Cao, J., and Yu, X. 2014. Genome-wide identification, phylogeny, duplication and expression analyses of two-component system genes in Chinese cabbage (Brassica rapa ssp. pekinensis). DNA Res. 21:379-396.

Livak, K. J., and Schmittgen, T. D. 2001. Analysis of relative gene expression data using real-time quantitative PCR and the $2^{-\Delta \Delta C T}$ method. Methods 25: 402-408.

Marcroft, S. J., Van de Wouw, A. P., Salisbury, P. A., Potter, T. D., and Howlett, B. J. 2012. Effect of rotation of canola (Brassica napus) cultivars with different complements of blackleg resistance genes on disease severity. Plant Pathol. 61:934-944.

Nagaharu, U. 1935. Genome analysis in Brassica with special reference to the experimental formation of B. napus and peculiar mode of fertilization. Jpn. J. Bot. 7:389-452.

Pecher, P., Eschen-Lippold, L., Herklotz, S., Kuhle, K., Naumann, K., Bethke, G., Uhrig, J., Weyhe, M., Scheel, D., and Lee, J. 2014. The Arabidopsis thaliana mitogen-activated protein kinases MPK3 and MPK6 target a subclass of 'VQ-motif'-containing proteins to regulate immune responses [published corrigendum appears in New Phytol. 2017;215:1623-1624]. New Phytol. 203:592-606.

Petersen, K., Fiil, B. K., Mundy, J., and Petersen, M. 2008. Downstream targets of WRKY33. Plant Signal. Behav. 3:1033-1034.

Petersen, K., Qiu, J. L., Lütje, J., Fiil, B. K., Hansen, S., Mundy, J., and Petersen, M. 2010. Arabidopsis MKS1 is involved in basal immunity and requires an intact $\mathrm{N}$-terminal domain for proper function. PLoS One 5: e14364.

Qiu, J. L., Fiil, B. K., Petersen, K., Nielsen, H. B., Botanga, C. J., Thorgrimsen, S., Palma, K., Suarez-Rodriguez, M. C., Sandbech-Clausen, S., Lichota, J., Brodersen, P., Grasser, K. D., Mattsson, O., Glazebrook, J., Mundy, J., and Petersen, M. 2008. Arabidopsis MAP kinase 4 regulates gene expression through transcription factor release in the nucleus. EMBO J. 27:2214-2221.

Raman, H., Raman, R., and Larkan, N. 2013. Genetic dissection of blackleg resistance loci in rapeseed (Brassica napus L.). Pages 85-120 in: Plant breeding from laboratories to fields. S. B. Andersen, ed. IntechOpen, Rijeka, Croatia.

Rouxel, T., and Balesdent, M. H. 2005. The stem canker (blackleg) fungus, Leptosphaeria maculans, enters the genomic era. Mol. Plant Pathol. 6: 225-241.

Rouxel, T., Grandaubert, J., Hane, J. K., Hoede, C., Van de Wouw, A. P., Couloux, A., Dominguez, V., Anthouard, V., Bally, P., Bourras, S., Cozijinsen, A. J., Ciuffetti, L. M., Degrave, A., Dilmaghani, A., Duret, L., Fudal, I., Goodwin, S. B., Gout, L., Glaser, N., Linglin, J., Kema, G. H., Lapalu, N., Lawrence, C. B., May, K., Meyer, M., Ollivier, B., Poulain, J., Schoch, C. L., Simon, A., Spatafora, J. W., Stachowiak, A., Turgeon, B. G., Tyler, B. M., Vincent, D., Weissenbach, J., Amselem, J., Quesneville, H., Oliver, R. P., Wincker, P., Balesdent, M. H., and Howlett, B. J. 2011. Effector diversification within compartments of the Leptosphaeria maculans genome affected by repeat-induced point mutation. Nat. Commun. 2:202.

Rouxel, T., Penaud, A., Pinochet, X., Brun, H., and Gout, L. 2003. A 10-year survey of populations of Leptosphaeria maculans in France indicates a rapid adaptation towards the Rlm1 resistance gene of oilseed rape. Eur. J. Plant Pathol. 109:871-881.
Shen, W., Cui, X., Li, H., Teng, R., Wang, Y., Liu, H., and Zhuang, J. 2019. Genome-wide identification and analyses of bHLH family genes in Brassica napus. Can. J. Plant Sci. 99:589-598.

Sonah, H., Zhang, X., Deshmukh, R. K., Borhan, M. H., Fernando, W. G. D., and Bélanger, R. R. 2016. Comparative transcriptomic analysis of virulence factors in Leptosphaeria maculans during compatible and incompatible interactions with canola. Front. Plant Sci. 7:1784.

Song, W., Zhao, H., Zhang, X., and Lai, J. 2016. Genome-wide identification of VQ motif-containing proteins and their expression profiles under abiotic stresses in maize. Front. Plant Sci. 6:1177.

Sprague, S. J., Balesdent, M. H., Brun, H., Hayden, H. L., Marcroft, S. J., Pinochet, X., Rouxel, T., and Howlett, B. J. 2006. Major gene resistance in Brassica napus (oilseed rape) is overcome by changes in virulence of populations of Leptosphaeria maculans in France and Australia. Eur. J. Plant Pathol. 114:33-40.

Sun, F., Fan, G., Hu, Q., Zhou, Y., Guan, M., Tong, C., Li, J., Du, D., Qi, C., Jiang, L., Liu, W., Huang, S., Chen, W., Yu, J., Mei, D., Meng, J., Zeng, P., Shi, J., Liu, K., Wang, X., Wang, X., Long, Y., Liang, X., Hu, Z., Huang, G., Dong, C., Zhang, H., Li, J., Zhang, Y., Li, L., Shi, C., Wang, J., Lee, S. M., Guan, C., Xu, X., Liu, S., Liu, X., Chalhoub, B., Hua, W., and Wang, H. 2017. The high-quality genome of Brassica napus cultivar 'ZS11' reveals the introgression history in semi-winter morphotype. Plant Biotechnol. J. 92:452-468.

Tamura, K., Steche, G., Peterson, D., Filipski, A., and Kumar, S. 2013. MEGA6: Molecular evolutionary genetics analysis version 6.0. Mol. Biol. Evol. 30:2725-2729.

Van de Wouw, A. P., Cozijnsen, A. J., Hane, J. K., Brunner, P., McDonald, B., Oliver, R., and Howlett, B. J. 2010. Evolution of linked avirulence effectors in Leptosphaeria maculans is affected by genomic environment and exposure to resistance genes in host plants. PLoS Pathog. 6:e1001180.

Voorrips, R. E. 2002. MapChart: Software for the graphical presentation of linkage maps and QTLs. J. Hered. 93:77-78.

Wang, A., Garcia, D., Zhang, H., Feng, K., Chaudhury, A., Berger, F., Peacock, W. J., Dennis, E. S., and Luo, M. 2010. The VQ motif protein IKU1 regulates endosperm growth and seed size in Arabidopsis. Plant J. 63: 670-679.

Wang, M., Vannozzi, A., Wang, G., Zhong, Y., Corso, M., Cavallini, E., and Cheng, Z. M. 2015. A comprehensive survey of the grapevine $V Q$ gene family and its transcriptional correlation with WRKY proteins. Front. Plant Sci. 6:417.

Wang, P., Yang, C., Chen, H., Luo, L., Leng, Q., Li, S., Han, Z., Li, X., Song, C., Zhang, X., and Wang, D. 2018. Exploring transcription factors reveals crucial members and regulatory networks involved in different abiotic stresses in Brassica napus L. BMC Genomics 18:202.

Wang, X., Wang, H., Wang, J., Sun, R., Wu, J., Liu, S., Bai, Y., Mun, J. H., Bancroft, I., Cheng, F., Huang, S., Li, X., Hua, W., Wang, J., Wang, X., Freeling, M., Pires, J. C., Paterson, A. H., Chalhoub, B., Wang, B., Hayward, A., Sharpe, A. G., Park, B. S., Weisshaar, B., Liu, B., Li, B., Liu, B., Tong, C., Song, C., Duran, C., Peng, C., Geng, C., Koh, C., Lin, C., Edwards, D., Mu, D., Shen, D., Soumpourou, E., Li, F., Fraser, F., Conant, G., Lassalle, G., King, G. J., Bonnema, G., Tang, H., Wang, H., Belcram, H., Zhou, H., Hirakawa, H., Abe, H., Guo, H., Wang, H., Jin, H., Parkin, I. A. P., Batley, J., Kim, J. S., Just, J., Li, J., Xu, J., Deng, J., Kim, J. A., Li, J., Yu, J., Meng, J., Wang, J., Min, J., Poulain, J., Wang, J., Hatakeyama, K., Wu, K., Wang, L., Fang, L., Trick, M., Links, M. G., Zhao, M., Jin, M., Ramchiary, N., Drou, N., Berkman, P. J., Cai, Q., Huang, Q., Li, R., Tabata, S., Cheng, S., Zhang, S., Zhang, S., Huang, S., Sato, S., Sun, S., Kwon, S., Choi, S., Lee, T. H., Fan, W., Zhao, X., Tan, X., Xu, X., Wang, Y., Qiu, Y., Yin, Y., Li, Y., Du, Y., Liao, Y., Lim, Y., Narusaka, Y., Wang, Y., Wang, Z., Li, Z., Wang, Z., Xiong, Z., and Zhang, Z.; Brassica rapa Genome Sequencing Project Consortium. 2011. The genome of the mesopolyploid crop species Brassica rapa. Nat. Genet. 43:1035-1039.

Wang, X., Zhang, H., Sun, G., Jin, Y., and Qiu, L. 2014. Identification of active VQ motif-containing genes and the expression patterns under low nitrogen treatment in soybean. Gene 543:237-243.

Wang, Y., Tang, H., DeBarry, J. D., Tan, X., Li, J., Wang, X., Lee, T. H., Jin, H., Marler, B., and Guo, H. 2012b. MCScanX: A toolkit for detection and evolutionary analysis of gene synteny and collinearity. Nucleic Acids Res. 40:e49.

Wang, Z., Mao, H., Dong, C., Ji, R., Cai, L., Fu, H., and Liu, S. 2009. Overexpression of Brassica napus MPK4 enhances resistance to Sclerotinia sclerotiorum in oilseed rape. Mol. Plant-Microbe Interact. 22:235-244.

Wang, Z., Tan, X., Zhang, Z., Gu, S., Li, G., and Shi, H. 2012a. Defense to Sclerotinia sclerotiorum in oilseed rape is associated with the sequential activations of salicylic acid signaling and jasmonic acid signaling. Plant Sci. 184:75-82.

Wei, L., Zhu, Y., Liu, R., Zhang, A., Zhu, M., Xu, W., Lin, A., Lu, K., and Li, J. 2019. Genome wide identification and comparative analysis of glutathione transferases (GST) family genes in Brassica napus. Sci. Rep. 9:9196. 
Wen, J., Guo, P., Ke, Y., Liu, M., Li, P., Wu, Y., Ran, F., Wang, M., Li, J., and $\mathrm{Du}, \mathrm{H}$. 2019. The auxin response factor gene family in allopolyploid Brassica napus. PLoS One 14:e214885.

West, J. S., Kharbanda, P. D., Barbetti, M. J., and Fitt, B. D. L. 2001. Epidemiology and management of Leptosphaeria maculans (Phoma stem canker) on oilseed rape in Australia, Canada and Europe. Plant Pathol. 50: 10-27.

Xie, Y. D., Li, W., Guo, D., Dong, J., Zhang, Q., Fu, Y., Ren, D., Peng, M., and Xia, Y. 2010. The Arabidopsis gene SIGMA FACTOR-BINDING PROTEIN 1 plays a role in the salicylate- and jasmonate-mediated defence responses. Plant Cell Environ. 33:828-839.

Xu, Y., Chang, P., Liu, D., Narasimhan, M. L., Raghothama, K. G., Hasegawa, P. M., and Bressan, R. A. 1994. Plant defense genes are synergistically induced by ethylene and methyl jasmonate. Plant Cell 6:1077-1085.

Yuan, D., Li, W., Hua, Y., King, G. J., Xu, F., and Shi, L. 2017. Genome-wide identification and characterization of the aquaporin gene family and transcriptional responses to boron deficiency in Brassica napus. Front. Plant Sci. 8:1336.

Zhang, G., Wang, F., Li, J., Ding, Q., Zhang, Y., Li, H., Zhang, J., and Gao, J. 2015. Genome-wide identification and analysis of the VQ motif-containing protein family in Chinese cabbage (Brassica rapa L. ssp. Pekinensis). Int. J. Mol. Sci. 16:28683-28704.

Zhang, J. 2003. Evolution by gene duplication: An update. Trends Ecol. Evol. 18:292-298.

Zhang, X., Peng, G., Kutcher, H. R., Balesdent, M. H., Delourme, R., and Fernando, W. G. D. 2016. Breakdown of Rlm3 resistance in the Brassica napus-Leptosphaeria maculans pathosystem in western Canada. Eur. J. Plant Pathol. 145:659-674.

Zheng, Z., Qamar, S. A., Chen, Z., and Mengiste, T. 2006. Arabidopsis WRKY33 transcription factor is required for resistance to necrotrophic fungal pathogens. Plant J. 48:592-605.

Zhou, Y., Yang, Y., Zhou, X., Chi, Y., Fan, B., and Chen, Z. 2016. Structural and functional characterization of the VQ protein family and VQ protein variants from soybean. Sci. Rep. 6:34663.

Zou, Z., Zhang, X., and Fernando, W. G. D. 2018. Distribution of mating-type alleles and genetic variability infield populations of Leptosphaeria maculans in western Canada. J. Phytopathol. 00:1-10.

Zou, Z., Zhang, X., Parks, P., du Toit, L. J., Van de Wouw, A. P., and Fernando, W. G. D. 2019. A new subclade of Leptosphaeria biglobosa identified from Brassica rapa. Int. J. Mol. Sci. 20:1668. 